\title{
Ruthenium-Catalyzed C-H Bond Activation Approach to Azolyl Aminals and Hemiaminal Ethers, Mechanistic Evaluations, and Isomer Interconversion
}

\author{
Manish K. Singh ${ }^{\dagger, \ddagger}$, Hari K. Akula ${ }^{\dagger, \ddagger, \S}$, Sakilam Satishkumar ${ }^{\dagger, \S}$, Lothar Stahlף, and Mahesh \\ K. Lakshman ${ }^{\dagger, \ddagger},{ }^{*}$ \\ tDepartment of Chemistry, The City College of New York, 160 Convent Avenue, New York, NY \\ 10031, United States \\ ¥The Ph.D. Program in Chemistry, The Graduate Center of The City University of New York, New \\ York, NY 10016, United States \\ IDepartment of Chemistry, The University of North Dakota, 151 Cornell Street Stop 9024, Grand \\ Forks, ND 58202, United States
}

\begin{abstract}
$\mathrm{C}\left(\mathrm{sp}^{3}\right)-\mathrm{N}$ bond-forming reactions between benzotriazole and 5,6-dimethylbenzotriazole with $\mathrm{N}$ methylpyrrolidinone, tetrahydrofuran, tetrahydropyran, diethyl ether, 1,4-dioxane, and isochroman have been conducted using $\mathrm{RuCl}_{3} \cdot 3 \mathrm{H}_{2} \mathrm{O} / t-\mathrm{BuOOH}$ in 1,2-dichloroethane. In all cases, $N 1$ and $N 2$ alkylation products were obtained, and these are readily separated by chromatography. One of these products, 1-(isochroman-1-yl)-5,6-dimethyl- $1 H$-benzotriazole, was examined by X-ray crystallography. It is the first such compound to be analyzed by this method, and notably, the benzotriazolyl moiety is quasi-axially disposed, consistent with the anomeric effect. This has plausible consequences, not observed previously. In contrast to other hemiaminal ether-forming reactions, which proceed via radicals, this Ru-catalyzed process is not suppressed in the presence of a radical inhibitor. Therefore, an oxoruthenium-species-mediated rapid formation of an oxocarbenium intermediate is believed to occur. In the radical-trapping experiment, previously unknown products containing both the benzotriazole and the TEMPO unit have been identified. In these products, it is likely that the benzotriazole is introduced via a Ru-catalyzed $\mathrm{C}-\mathrm{N}$ bond formation, whereas $\mathrm{C}-\mathrm{O}$ bond-formation with TEMPO occurs via a radical reaction. We show that reactions of THF with TEMPO are influenced by ambient light. A competitive reaction of THF
\end{abstract}

\footnotetext{
${ }^{*}$ Corresponding Author: mlakshman@ccny.cuny.edu.

$\S$ These coauthors contributed equally to the work (H.K.A. and S.S.).

The authors declare no competing financial interest.

Supporting Information

Experimental procedures for synthesis of all compounds described, ${ }^{1} \mathrm{H}$ and ${ }^{13} \mathrm{C}$ NMR spectra of compounds $\mathbf{5}, \mathbf{8 a}-\mathbf{2 1 a}, \mathbf{8 b}-\mathbf{2 1 b}, \mathbf{2 2}$, 23a, 23b, 25-28, DEPT, HMBC, and NOESY spectra of compound 5, gCOSY and NOESY spectra of compound 20a, ${ }^{1} \mathrm{H},{ }^{13} \mathrm{C}$, and ${ }^{2} \mathrm{H}$ NMR spectra of mixtures of $\mathbf{1 2 a}+\mathbf{1 2} \mathbf{a}-\not h$ as well as $\mathbf{1 2 b}+\mathbf{1 2} \mathbf{b}-\not h$, partial gCOSY and NOESY spectra of $\mathbf{2 3 a},{ }^{1} \mathrm{H}$ NMR spectrum of $\mathbf{2 4}$, HRMS spectrum showing an ion corresponding to the $N 2$ isomer of $\mathbf{2 8},{ }^{1} \mathrm{H}$ NMR spectra showing the formation of 1 (2-chloroethyl)-1 $H$-imidazole, ${ }^{1} \mathrm{H}$ NMR and HRMS spectra corresponding to 2-( $t$-butylperoxy)tetrahydrofuran, $\mathrm{X}$-ray data for compound 21a and CIF file, details on additional mechanistic experiments that were conducted, stacked ${ }^{1} \mathrm{H}$ NMR plots for the isomerization of compound $\mathbf{2 0 b}$ to $\mathbf{2 0 a}, \mathbf{1 2 b}$ to $\mathbf{1 2 a}, \mathbf{1 2 a}$ to $\mathbf{1 2 b}$, and thermal conversion of compound 12b to 12a. This information is available free of charge via the Internet at http://pubs.acs.org.
} 
and THF- $d_{8}$ with benzotriazole indicated that $\mathrm{C}-\mathrm{H}$ bond cleavage occurs $c$. 5 times faster than $\mathrm{C}-$ $\mathrm{D}$ cleavage. This is comparable to other metal-mediated radical reactions of THF, but lower than that observed for a reaction catalyzed by $n-\mathrm{Bu}_{4} \mathrm{~N}^{+} \mathrm{I}^{-}$. Detailed mechanistic experiments and comparisons are described. The catalytic system was also evaluated for reactions of benzimidazole, imidazole, 1,2,4-triazole, and 1,2,3-triazole with THF, and successful reactions were achieved in each case. In the course of our studies, we discovered an unexpected but significant isomerization of some of the benzotriazolyl hemiaminal ethers. This is plausibly attributable to the pseudoaxial orientation of the heterocycle in the products and the stability of oxocarbenium ions, both of which can contribute to $\mathrm{C}-\mathrm{N}$ bond cleavage and reformation. Predominantly, the $N 2$-isomers rearrange to the $N 1$-isomers even upon storage at low temperature! This previously unknown phenomenon has also been studied and described.

\section{Graphical Abstract}

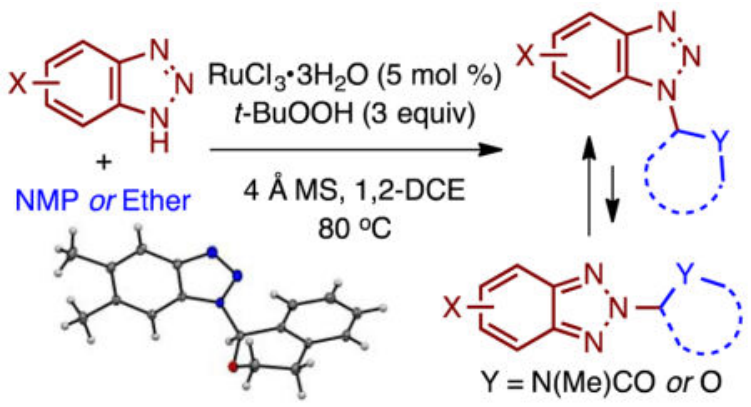

\section{Keywords}

$\mathrm{C}-\mathrm{H}$ bond activation; azole; ruthenium catalysis; ether; $\mathrm{N}$-methylpyrrolidinone; aminal; hemiaminal ether

\section{INTRODUCTION}

$\mathrm{N}$-directed $\mathrm{C}-\mathrm{H}$ bond activation followed by $\mathrm{C}-\mathrm{C}$ bond formation is an economical, environmentally-friendly method to functionalize diverse organic molecules, ${ }^{1}$ and such transformations can be accomplished with a variety of transition-metal catalysts. ${ }^{2}$ Within the context of nucleoside and purine modification, we $e^{3,4}$ and others ${ }^{5,6}$ have utilized the embedded purinyl nitrogen atoms to accomplish remote functionalizations of aromatic rings. In general, $\mathrm{C}-\mathrm{H}$ bond activation has now become an important approach to late-stage functionalization of the labile polynitrogenated nucleosides and related heterocycles in ways that are otherwise not trivial. ${ }^{7}$

We have previously reported synthesis of 1,4-disubstituted 1,2,3-triazoles wherein the $N 1$ substituent was a purine nucleoside. ${ }^{8,9}$ Among these compounds, some C- 6 triazolyl purine nucleosides showed weak antiproliferative activity against ovarian and colorectal carcinoma cell lines. Therefore, for additional SAR studies, we considered $\mathrm{N}$-directed $\mathrm{C}-\mathrm{H}$ bond activation for further functionalizing C-6 triazolyl nucleosides. For this, we chose to evaluate 
$\mathrm{Ru}$ catalysis on the basis of the ortho-arylation reactions of C-6 aryl nucleosides using the purinyl nitrogen atom. ${ }^{4}$

In the course of these investigations, we encountered an unusual scission of the $\mathrm{C}-\mathrm{N}$ bond between the nucleoside and the triazole, followed by $\mathrm{C}-\mathrm{H}$ bond activation of the solvent, NMP, and $\mathrm{C}-\mathrm{N}$ bond formation with the released triazole. This observation led us to initially investigate Ru-catalyzed $\mathrm{C}-\mathrm{H}$ bond activation of NMP and, subsequently, comparable reactions of a variety of ethers. This article describes the first Ru-catalyzed formation of benzotriazolyl aminals from NMP and azolyl hemiaminal ethers by $\mathrm{C}-\mathrm{H}$ bond activation, mechanistic and structural studies, comparisons to the generally sparse, recently published data on such reactions, and the observation of a previously undocumented interconversion of isomeric products.

\section{Results and Discussion}

In the context of $\mathrm{N}$-directed remote functionalization, we were interested in the hyperfunctionalization of C- 6 triazolyl nucleosides. Therefore, nucleoside $\mathbf{1}^{8}$ was exposed to $\mathrm{PhBr}\left(2\right.$ equiv) and a catalytic system composed of $\left[\mathrm{RuCl}_{2}\left(\eta^{6} \mathrm{PhH}\right)\right]_{2}(5 \mathrm{~mol} \%) / \mathrm{Ph}_{3} \mathrm{P}(20$ mol \%)/ $\mathrm{K}_{2} \mathrm{CO}_{3}$ (4 equiv) (Scheme 1). ${ }^{10}$ However, this reaction did not yield the expected product 2 , but a non-nucleosidic product was obtained in 32\% yield. NMR experiments showed that it was derived from $N$-methylpyrrolidinone (NMP) and contained the phenyl triazolyl moiety. ${ }^{13} \mathrm{C}$ NMR, DEPT data, and the weak NOE observed between the triazolyl $\mathrm{H} 5$ proton and the $\mathrm{N}-\mathrm{Me}$ resonances pointed to isomer $\mathbf{5}$ as the possible product of the reaction among three isomeric possibilities 3-5 (Scheme 1).

A second experiment without $\mathrm{PhBr}$ also led to product 5 in a comparable $34 \%$ yield. However, in this attempt $3^{\prime}, 5^{\prime}$-di- $O$-(tert-butyldimethylsilyl)-2' -deoxyinosine (6) was observed in the product mixture. Thus, the nucleoside appeared to function as the source of a triazole, and in the process, it acts as a leaving group. On the basis of this outcome, we then tested the use of Bt-OTs (7), a triazole bearing a leaving group, using the same catalytic system (Scheme 2).

The reaction of NMP with Bt-OTs gave products $\mathbf{8 a}$ and $\mathbf{8 b}$ in reasonable 51 and $18 \%$ yields, respectively. Given the result of this reaction, and with a view to improved atom economy, the use of $1 H-1,2,3$-benzotriazole $(\mathrm{BtH})$ was then evaluated (Scheme 2). This reaction gave much poorer yields of products $8 \mathbf{a}$ and $\mathbf{8 b}$ (28 and 5\%, respectively), but the chemistry appeared feasible. Another problem was the contamination of the more-polar $N 1$ isomer with $\mathrm{Ph}_{3} \mathrm{PO}$. Although compound $\mathbf{8 a}$ and $\mathbf{8 b}$ are not known to our knowledge, a product comparable to $\mathbf{8 a}$ from benzimidazole has been obtained via catalysis by $\mathrm{FeCl}_{2}$ with $(t-\mathrm{BuO})_{2}$ in $\mathrm{PhCl}$ at $120{ }^{\circ} \mathrm{C} .{ }^{11}$ In that work, ${ }^{11} \mathrm{C}-\mathrm{N}$ bond formation with the methyl group was also observed, which was not observed here. On the basis of the foregoing, we analyzed other conditions, including those involving an oxidant, for the reaction of BtH with NMP (Table 1).

Some notable points emerge from Table 1. $N 1$ - and $N 2$-alkylated products were observed in every case, and the combined product yields were modest in several initial experiments 
(entries 1-4). Use of $\mathrm{O}_{2}$ gas in entries 1-4 was based on the Ru-catalyzed aerobic, oxidativecyanation of tertiary amines. ${ }^{12}$ With the benzene- and $p$-cymene-Ru complexes product purities were high, and the overall yield was better with the former despite a slower reaction (entry 1 versus 2). Use of $\left[\mathrm{Ru}(\mathrm{CO})(\mathrm{H})_{2}\left(\mathrm{PPh}_{3}\right)_{3}\right]$ resulted in an incomplete reaction even after $48 \mathrm{~h}$ (entry 3). We then tested the cheaper $\mathrm{RuCl}_{3} \cdot 3 \mathrm{H}_{2} \mathrm{O}$ (entry 4). In combination with $t$ $\mathrm{BuOOH}$, a significantly faster reaction occurred, which was complete at room temperature (entry 5).

In entries 1-6, NMP was used both as reaction solvent and reagent. Thus, efforts were directed toward reducing the NMP (entries 6-8). In comparing entries 6 and 7, lowering $\mathrm{NMP}$ to 3 equiv and $t \mathrm{BuOOH}$ to 2.5 equiv slowed the reaction and caused a drastic decrease in overall yield. A reaction in 1,2-dichloroethane (DCE) with 10 equiv NMP, a lowered $5 \mathrm{~mol} \%$ of the Ru catalyst, 3 equiv $t-\mathrm{BuOOH}$ (in nonane), and in the absence of $\mathrm{K}_{2} \mathrm{CO}_{3}$, gave a good overall product yield, with a higher proportion of the $N 1$ isomer (entry 8). When no catalyst was used, an incomplete reaction occurred in $29 \mathrm{~h}$ at $80^{\circ} \mathrm{C}$, indicating that a slow, background reaction could still occur, possibly via decomposition of $t \mathrm{BuOOH}$ (entry 9). This possibility is consistent with a recent observation that $(t-\mathrm{BuO})_{2}$, and to a lesser extent $t$ - $\mathrm{BuOOH}$, can produce radical intermediates from isochroman, 1,3dihydrobenzofuran, $\mathrm{N}$-substituted tetrahydroisoquinolines, 1,4-dioxane, and THF. ${ }^{13}$ Notably, $t$ - $\mathrm{BuOOH}$ in water was ineffective for this purpose, whereas a solution in decane gave modest product formation with indole (leading to C-3 alkylation). ${ }^{13}$

On the basis of these results, conditions in entry 8 were utilized for subsequent experiments, and their applicability to the reactions of BtH (9) and commercially available 5,6dimethyl-1 $H$-1,2,3-benzotriazole (5,6-DMBtH, 10) was tested. Because two products are anticipated in these reactions, use of the symmetrical benzotriazole renders the separation problem simpler. Results from the reactions of these two $1 H$-benzotriazoles are presented in Table 2. It should be noted that in initial experiments involving ethers, two reactions of THF with $\mathrm{BtH}$ using catalyst from two different sources were observed to be incomplete in the absence of $4 \AA$ molecular sieves (MS). Thus, sieves have been used in reactions involving ethers.

In every case, $N 1$ and $N 2$ alkylated products were formed, and these were readily separated by chromatography. The $N 1$ isomers are significantly more polar on silica gel as compared to the $N 2$ isomers, and in their ${ }^{1} \mathrm{H}$ NMR spectra, the benzotriazolyl proton resonance pattern of the former is more complex, consistent with the lack of symmetry. Because the products from the reactions of isochroman are solids, the $N 1$ isomer obtained from the reaction of 5,6-DMBtH with isochroman (21a) was crystallized, and its single-crystal X-ray structure was obtained (Figure 1). ${ }^{14}$ This structure shows that $\mathrm{C}-\mathrm{N}$ bond formation occurred, alpha to the ether oxygen, at the more activated benzylic position. Notably, the structure demonstrates the quasi-axial disposition of the benzotriazolyl ring, consistent with the anomeric effect. This is the first time a product of this type has been crystallographically characterized.

In order to assess whether this reaction would be applicable to other types of ethers, we conducted a preliminary evaluation on the ability of an alcohol silyl ether to undergo this $\mathrm{C}-$ 
$\mathrm{H}$ bond activation (Scheme 3). In a reaction of 2-phenylethanol TBDMS ether with $\mathrm{BtH}$, the latter was not completely consumed even after $96 \mathrm{~h}$, and $N \mathrm{l}$ isomer 22 was isolated in $11 \%$ yield. The fact that this is not an uncatalyzed process is indicated by the reduction in yield by half upon reducing the catalyst loading by half. In addition to a slow reaction, silyl group instability to the reaction conditions and product lability could be contributing reasons for the low yield. Importantly though, formation of product $\mathbf{2 2}$ indicates that other ethers, such as silyl ethers, may also potentially be substrates for $\mathrm{C}-\mathrm{H}$ bond-activation reactions, an aspect that had not been investigated to date. In its ${ }^{1} \mathrm{H}$ NMR spectrum, compound $\mathbf{2 2}$ displayed a one-proton doublet of doublets ( $\delta_{\mathrm{X}}=6.59 \mathrm{ppm}, J=4.9 \mathrm{~Hz}, 8.0 \mathrm{~Hz}$ ), a two proton doublet of an $\mathrm{AB}_{\text {quartet }}\left(\delta_{\mathrm{A}}=3.33\right.$ and $\delta_{\mathrm{B}}=3.48 \mathrm{ppm}, J_{\mathrm{AX}}=4.9 \mathrm{~Hz}, J_{\mathrm{BX}}=8.0 \mathrm{~Hz}$, $\left.J_{\mathrm{AB}}=13.7 \mathrm{~Hz}\right)$, and diastereotopic silyl methyl resonances $(\delta=-0.13$ and $-0.36 \mathrm{ppm})$, as would be expected of this chiral compound.

To gain some insight into the mechanism, a reaction of BtH and THF was performed in the presence of TEMPO (2,2,6,6-tetramethyl-1-piperidinyloxy, Scheme 4) under the optimized reaction conditions. Practically no inhibition of the reaction was observed, and the $N \mathrm{l}$ - and $N 2$-THF adducts 12a and 12b were obtained in 48 and 24\% yield, respectively. In addition, two minor elusive products, 23a and $\mathbf{2 3 b}$, were isolated in 10 and 5\% yield, respectively. The combined yield of all products obtained in this reaction was $87 \%$ (compared to the $84 \%$ in entry 3 of Table 2). Compounds 23a and 23b have never been identified in comparable reactions, and their structures were assigned by a combination of NMR and HRMS analyses. Not observing these minor products could have led us to believe that some attenuation of the reaction had occurred. Both compounds exhibit benzotriazolyl resonances, with aryl proton resonances comparable to those in compounds 12a and 12b, but in both cases, additional aliphatic resonances from TEMPO are observed.

Despite small variations in the chemical shifts of the tetrahydrofuranyl protons in isomeric compounds 23a and $\mathbf{2 3 b}$, the overall patterns and coupling constants of these protons are very similar (Figure 2). ${ }^{15}$ Thus, it can be anticipated that the stereochemical arrangement of the benzotriazolyl and the piperidinyloxy groups in both compounds are identical. Analysis of the NOESY spectrum of compound 23a indicated a strong interaction between the two protons at the anomeric carbon atoms, supporting the structures as indicated in Figure 2, with a cis arrangement of the two substituents. The chemical shift of $\mathrm{H}^{\prime}{ }^{\prime}$ was similar to that in compound 12a and it showed NOE correlation with a benzotriazolyl proton.

A competitive reaction of THF and THF- $d_{8}$ with $\mathrm{BtH}$ was conducted under the general conditions in order to assess the kinetic isotope effect (KIE). As shown in Scheme 5, four products are anticipated. A mixture of compound 12a and its deuterated analogue 12a- $d_{7}$ were collected as one fraction as was the mixture of the isomeric compounds $\mathbf{1 2 b}$ and $\mathbf{1 2 b}$ $d_{7}$. The combined yield of purified products from this reaction was $80 \%$ and the $N 1 / N 2$ isomer ratio was 4:1 (both comparable to data in entry 3 of Table 2). From the integration of the benzotriazolyl resonances in the ${ }^{1} \mathrm{H}$ NMR spectrum of the major $N 1$ isomer fraction, the ratio of 12a/12a- $d_{7}$ was determined to be 5.2:1. From HRMS analysis, the ratio of the $[\mathrm{M}+$ $\mathrm{Na}]^{+}$ions for the two products in this fraction was 5.5:1. Similarly, by ${ }^{1} \mathrm{H}$ NMR, the ratio of $\mathbf{1 2} \mathbf{b} / \mathbf{1 2 b}-d_{7}$ in minor $N 2$ isomer fraction was $5.7: 1$, whereas the $[\mathrm{M}+\mathrm{Na}]^{+}$ion ratio in this case was observed to be 6.1:1. 
While this work was in progress, three other reports involving reactions of benzotriazole with ethers have appeared: (a) those of 1,4-dioxane and THF using $\mathrm{FeCl}_{3} / t-\mathrm{BuOOH}$ (neat at $100{ }^{\circ} \mathrm{C}$ ), ${ }^{16}$ (b) that of THF using $n-\mathrm{Bu}_{4} \mathrm{~N}^{+} \mathrm{I}^{-} / t-\mathrm{BuOOH}$ (neat, sealed tube at $\left.75{ }^{\circ} \mathrm{C}\right),{ }^{17}$ and (c) those of THF, 1,4-dioxane, $\mathrm{Et}_{2} \mathrm{O}$, and dihydropyran also using $n-\mathrm{Bu}_{4} \mathrm{~N}^{+} \mathrm{I}^{-} / t$ - $\mathrm{BuOOH}$ (DCE, $\left.80{ }^{\circ} \mathrm{C}\right) .{ }^{18}$ Although a mechanistic assessment of the $\mathrm{FeCl}_{3}$-catalyzed reactions of benzotriazole is not available, and neither are exactly comparable data in the other cases, KIE values have been reported for hemiaminal ether formation from imidazole and carbazole. ${ }^{19,20}$ These data along with reaction conditions are shown in Table 3 and the results implicate a slow hydrogen atom abstraction step. ${ }^{19,20}$ The KIE observed in the current competition experiment is comparable to these prior metal-catalyzed reactions. Because formation of a reactive intermediate from THF is a likely occurrence before a product-forming step, we propose that $\mathrm{C}-\mathrm{H}$ bond cleavage occurs in the slow step. In contrast to the KIE in metal-mediated processes, that observed for the $n$ - $\mathrm{Bu}_{4} \mathrm{~N}^{+} \mathrm{I}^{-}$-catalyzed reaction is reported as 15.7 (entry 3 in Table 3 ). ${ }^{17}$

Previously reported reactions of benzimidazole, ${ }^{18}$ imidazole,${ }^{19}$ and carbazole ${ }^{20}$ with THF were suppressed in the presence of TEMPO, and the radical formed from THF was captured by TEMPO (for a structure of the TEMPO-THF adduct, see compound $\mathbf{2 4}$ in Scheme 6). This is a major difference in this work because TEMPO neither inhibited the reaction nor was the THF-TEMPO adduct observed. Therefore, the present mechanism has to account for a slow step involving loss of " $\mathrm{H}$ " without radical intermediates, or if radicals are produced they must be extremely short-lived to escape capture by TEMPO. A first step in the reaction is the likely formation of an oxoruthenium intermediate by the reaction of $\mathrm{RuCl}_{3}$ with $t$ $\mathrm{BuOOH}$. This is supported by the fact that only a trace of product was observed when the reaction was conducted in the absence of $t \mathrm{BuOOH}$. Another difference between this work and prior mechanistic studies on the reaction of imidazole with THF using $\mathrm{FeCl}_{3} \cdot 6 \mathrm{H}_{2} \mathrm{O} / t$ $\mathrm{BuOOH},{ }^{19}$ is the presence of $4 \AA \mathrm{MS}$ in our reactions. Thus, we repeated the reported radical inhibition experiment ${ }^{19}$ in the presence of $4 \AA$ MS, with a very similar outcome. This indicated that molecular sieves do not influence the mechanistic course.

Next, three reactions of THF (10 equiv) and TEMPO (1 equiv) were conducted in the presence of $t \mathrm{BuOOH}$, under ambient laboratory light, under subdued light, and protected from light (see Figure S1 in the Supporting Information). The reaction conducted under laboratory light became colorless, and complete consumption of TEMPO was observed with formation of the TEMPO-THF adduct 24. On the other hand, the reaction under subdued light and that protected from light remained orange, and showed a substantial amount of residual TEMPO (by TLC analysis, ca. 30\% of adduct $\mathbf{2 4}$ was observed, eq 1 in Scheme 6). Thus, this reaction of TEMPO with THF may be accelerated by ambient light.

Experiments were then conducted between $\mathrm{BtH}$ and THF in the presence of $t \mathrm{BuOOH}$, under the optimized conditions, but without the catalyst (eq 2 in Scheme 6). One reaction was performed under ambient laboratory lighting, and the other was protected from light. Results from both reactions were comparable, yielding $28-29 \%$ of the $N 1$ isomer 12a, 9$10 \%$ of the $N 2$ isomer $\mathbf{1 2 b}$, and $58-59 \%$ of recovered $\mathrm{BtH}$. These collective results indicate that a radical reaction leading to products is possible, and this process is abrogated by TEMPO (eq 3 in Scheme 6). However, this radical process appears to not significantly 
contribute to the reaction in the presence of the Ru catalyst, because no inhibition by TEMPO was observed and good product yields ensued. Finally, to ensure that a reaction between TEMPO and the Ru catalyst was not responsible for false indications, a $\mathrm{RuCl}_{3}$ catalyzed reaction of $\mathrm{BtH}$ and THF was conducted in the absence of $t \mathrm{BuOOH}$ but with added TEMPO (eq 4 in Scheme 6). Only a trace of product was observed in this reaction and a substantial amount of TEMPO remained. Thus, in the radical inhibition experiment, TEMPO neither contributes to product formation nor is it destroyed by the catalyst.

On the basis of the foregoing discussion, we propose the mechanism shown in Scheme 7. This is similar to that involved in the Ru-catalyzed oxidation of alkanes, wherein an oxoruthenium intermediate has been proposed. ${ }^{21}$ This intermediate then reacts with the ether producing a resonance-stabilized oxocarbenium ion, which is then captured by $\mathrm{BtH}$. As mentioned earlier, there is a caveat. Although reaction inhibition was not observed with TEMPO, if rapid electron-transfer processes occur, then a very short-lived radical intermediate may elude capture.

As regards formation of products $\mathbf{2 3 a}$ and $\mathbf{2 3 b}$, we have to surmise that they arise by a metal-independent radical process at one of two stages: (a) due to ambient light, a minor background reaction of THF with TEMPO produces the TEMPO addition product, and this undergoes $\mathrm{C}-\mathrm{H}$ bond activation, or (b) product formation occurs first, and then compounds 23a and $\mathbf{2 3 b}$ are formed by the minor radical reaction due to ambient light.

Because a few different catalytic approaches to benzotriazolyl hemiaminal ethers have emerged while this work was in progress, we offer a comparison of known data to those obtained here (Table 4). Notably, these previous reports ${ }^{16-18}$ only describe reactions of BtH. As reactions can depend upon the structure of the benzotriazole, 5,6-DMBtH has also been evaluated in this work so as to offer a comparison to reactions of $\mathrm{BtH}^{22} \mathrm{In} \mathrm{FeCl}_{3}$-catalyzed reactions of BtH with THF and 1,4-dioxane, ${ }^{16}$ as well as in a $n-\mathrm{Bu}_{4} \mathrm{~N}^{+} \mathrm{I}^{-}$-catalyzed reaction of BtH with THP, ${ }^{18}$ no $N 2$ isomers were reported. Because formation of both isomers is reported for other ethers, and has been observed herein, we wonder whether these prior reactions led to only a single isomer, or whether the $N 2$ isomers were formed in low amounts, or were lost during isolation procedures, or rearranged (see below). Also interesting to note is that even with an identical reagent combination but under different conditions, ${ }^{17,18}$ variability in the $N \mathrm{l} / N 2$ ratios seems possible (see reactions of THF using $n$ $\mathrm{Bu}_{4} \mathrm{~N}^{+} \mathrm{I}^{-} / t-\mathrm{BuOOH}$ in Table 4).

After these evaluations involving benzotriazoles were completed, we assessed whether the reaction conditions could be applied to other azoles, and we selected benzimidazole, imidazole, 1,2,4-triazole, and 1,2,3-triazole for analysis. Reactions were conducted with THF, and the products, reaction times, as well as yields are shown in Figure 3.

The reaction of benzimidazole proceeded uneventfully under the optimized conditions, but that of imidazole was complicated by the formation of inseparable 1-(2-chloroethyl)- $1 \mathrm{H}$ imidazole by $\mathrm{N}$-alkylation with DCE. This side reaction has either not been observed or reported in the $\mathrm{FeCl}_{3}$-catalyzed reaction of imidazole with THF. ${ }^{19}$ Due to the formation of this undesired byproduct, we conducted the reaction of imidazole in THF as solvent, and this 
resulted in a reasonable product yield. 1,2,4-Triazole reacted very cleanly resulting in only the $N \mathrm{l}$ product (as evidenced by two aryl proton resonances in the ${ }^{1} \mathrm{H}$ NMR spectrum). This regiochemical outcome is comparable to those observed in reactions mediated by $n$ $\mathrm{Bu}_{4} \mathrm{~N}^{+} \mathrm{I}^{-} / t-\mathrm{BuOOH}^{18}$ and $\mathrm{FeCl}_{3} / t-\mathrm{BuOOH} .{ }^{19}$ In the reaction of 1,2,3-triazole, the $N 1$ product predominated, although HRMS data indicated that another chromatographically isolated fraction may contain a trace of the $N 2$ isomer. However, in the latter three reactions, a product was isolated that appears to be 2 -( $t$-butylperoxy)tetrahydrofuran ${ }^{23}$ (see the Supporting Information). The role of this species, if any, is currently not known. Table 5 offers a comparison of the reaction of these four heterocycles with THF under the various conditions.

Finally, an unanticipated observation was made when we reanalyzed the ${ }^{1} \mathrm{H}$ NMR spectrum of 2-(isochroman-1-yl)-2 $H$-benzotriazole (20b) after storage at $2-5{ }^{\circ} \mathrm{C}$ for a period of $c a .6$ months. This material had undergone almost complete isomerization to 1-(isochroman-1yl)- $1 H$-benzotriazole (20b, see Figure S2 in the Supporting Information). Therefore, we also obtained ${ }^{1} \mathrm{H}$ NMR spectra of the THF-derived compounds $\mathbf{1 2 a}$ and $\mathbf{1 2 b}$. A very old sample of compound 12b had undergone substantial conversion to the $N 1$-isomer 12a (see Figure S3 in the Supporting Information), but the $\mathrm{Nl}$-isomer had converted to only a minor amount of the $N 2$-isomer (see Figure S4 in the Supporting Information).

Because isomerization of the tetrahydrofuranyl compound occurred but was very slow, we performed an experiment to increase the rate of this interconversion. A neat sample of 2(tetrahydrofuran-2-yl)-2H-1,2,3-benzotriazole (12b) was heated in a NMR tube, and the conversion was monitored periodically (solvent was added for obtaining a spectrum and then evaporated off prior to continued heating). As seen from Figure 4, clean conversion to 1(tetrahydrofuran-2-yl)-1 $H$-1,2,3-benzotriazole (12a) occurred (see Figure S5 in the Supporting Information for additional time points). On the basis of these observations it appears that the ratio of the $N 1$ and $N 2$ isomers can be altered by a number of factors, which can include not only reaction conditions but also those for storage.

The interconversion could occur by $\mathrm{C}-\mathrm{N}$ bond scission, enabled by the pseudoaxial orientation of the departing group (benzotriazole) at an anomeric position, followed by a $\mathrm{C}-$ $\mathrm{N}$ bond reformation, proceeding via an oxocarbenium ion (Scheme 8). In such an event, 2 (isochroman-1-yl)-2 $H$-benzotriazole (20b) will be expected to isomerize faster as compared to 2-(tetrahydrofuran-2-yl)-2H-1,2,3-benzotriazole (12b), due to the increased stability of an oxocarbenium intermediate from the former. The driving force for rearomatization of the aryl ring readily explains the $N 2$ to $N 1$ interconversion. In fact, these factors may also help explain the relatively large $N 1 / N 2$ isomer ratios observed in the reactions of isochroman (entries 11 and 12 in Table 2) as compared to other reactions. It is currently not clear why a minor $N 1$ to $N 2$ conversion occurs. Nevertheless, such an interconversion of isomers has not been reported previously in the context of similar reactions.

\section{CONCLUSIONS}

In conclusion, ruthenium-catalyzed functionalization of $\mathrm{sp}^{3}$ carbon atoms adjacent to the nitrogen atom of a lactam (NMP) and the oxygen atom of five ethers with BtH and 5,6- 
DMBtH has been demonstrated. The reaction also appears applicable to benzimidazole, imidazole, 1,2,4-triazole, and 1,2,3-triazole, as evidenced by their reactions with THF. For the first time, in a preliminary result, this method was shown to produce functionalization adjacent to a $\mathrm{O}-\mathrm{Si}$ bond, albeit only in low yield. One product, from the reaction of 5,6$\mathrm{DMBtH}$ with isochroman, was crystallized and characterized by X-ray analysis. This revealed that the benzotriazolyl moiety is quasi-axially disposed due to the anomeric effect. From a mechanistic consideration, the Ru-catalyzed process appears to rapidly produce heteroatom-stabilized carbenium ions, which are then trapped by the azoles. $\mathrm{C}-\mathrm{H}$ bond cleavage occurs ca. 5 times faster than $\mathrm{C}-\mathrm{D}$ cleavage and does not appear to involve radical intermediates, at least not long-lived ones. This is a mechanistic departure from similar $\mathrm{C}-\mathrm{H}$ bond activation processes of ethers. In the attempted radical trapping experiment, two unusual and previously undescribed products, containing benzotriazolyl and TEMPO moieties, have been identified. It appears that the benzotriazolyl unit is introduced by the metal-mediated $\mathrm{C}-\mathrm{N}$ bond formation, whereas the TEMPO moiety is incorporated by a minor background $\mathrm{C}-\mathrm{O}$ bond formation via a radical process. Interestingly, some of the products, particularly the $N 2$-alkylated derivatives, undergo isomerization to the $N 1$-alkyl compounds even under such mild conditions as storage at low temperature. By heating a neat sample of 2-(tetrahydrofuran-2-yl)- $2 H$-1,2,3-benzotriazole at $50{ }^{\circ} \mathrm{C}$, this transformation has been monitored by ${ }^{1} \mathrm{H}$ NMR spectroscopy.

Caution! Although there are several documented examples involving the use of ruthenium salts in combination with peroxides, appropriate caution should be exercised while handling these materials and their combinations.

\section{Supplementary Material}

Refer to Web version on PubMed Central for supplementary material.

\section{Acknowledgments}

Financial support of this work by NSF grant CHE-1265687 (MKL) is gratefully acknowledged. Infrastructural support at CCNY was provided by NIH grant G12MD007603 from the National Institute on Minority Health and Health Disparities. We thank Dr. Lijia Yang (CCNY) for some high-resolution mass spectral data.

\section{References}

1. (a) Dyker, G., editor. Handbook of C H Transformations: Applications in Organic Synthesis. Vol. 1 and 2. Wiley-VCH; Weinheim: 2005. (b) Kakiuchi, F.; Murai, S. Activation of Unreactive Bonds and Organic Synthesis. Murai, S., editor. Springer; Berlin: 1999. p. 4-79.

2. For recent reviews on nitrogen directed $\mathrm{C} \mathrm{H}$ bond activation see: Louillat ML, Patureau FW. Chem Soc Rev. 2014; 43:901-910. [PubMed: 24217419] Thirunavukkarasu VS, Kozhushkov SI, Ackermann L. Chem Commun. 2014; 50:29-39.Kapdi AR. Dalton Trans. 2014; 43:3021-3034. [PubMed: 24419051] Rouquet G, Chatani N. Angew Chem, Int Ed. 2013; 52:11726-11743.JuliáHernández F, Simonetti M, Larrosa I. Angew Chem, Int Ed. 2013; 52:11458-11460.Arockiam PB, Bruneau C, Dixneuf PH. Chem Rev. 2012; 112:5879-5918. [PubMed: 22934619] Zhu C, Wang R, Falck JR. Chem Asian J. 2012; 7:1502-1514. [PubMed: 22492555] Mei TS, Kou L, Ma S, Engle KM, Yu JQ. Synthesis. 2012; 44:1778-1791. [PubMed: 27397938] Lyons TW, Sanford MS. Chem Rev. 2010; 110:1147-1169. [PubMed: 20078038] Colby DA, Tsai AS, Bergman RG, Ellman JA. Acc Chem Res. 2012; 45:814-825. [PubMed: 22148885] Colby DA, Bergman RG, Ellman JA. Chem Rev. 2010; 110:624-655. [PubMed: 19438203] Campos KR. Chem Soc Rev. 2007; 36:10691084. [PubMed: 17576475] Godula K, Sames D. Science. 2006; 312:67-72. [PubMed: 16601184] 
3. Chamala RR, Parrish D, Pradhan P, Lakshman MK. J Org Chem. 2013; 78:7423-7435. [PubMed: 23844876]

4. Lakshman MK, Deb AC, Chamala RR, Pradhan P, Pratap R. Angew Chem, Int Ed. 2011; 50:1140011404.

5. (a) Wang DC, Niu HY, Xie MS, Qu GR, Wang HX, Guo HM. Org Lett. 2014; 16:262-265. [PubMed: 24328807] (b) Qu GR, Liang L, Niu HY, Rao WH, Guo HM, Fossey JS. Org Lett. 2012; 14:4494-4497. [PubMed: 22900616] (c) Guo HM, Jiang LL, Niu HY, Rao WH, Liang L, Mao RZ, Li DY, Qu GR. Org Lett. 2011; 13:2008-2011. [PubMed: 21434677]

6. (a) Patel P, Chang S. ACS Catal. 2015; 5:853-858.(b) Pawar AB, Chang S. Org Lett. 2015; 17:660663. [PubMed: 25602639] (c) Kim HJ, Ajitha MJ, Lee Y, Ryu J, Kim J, Lee Y, Jung Y, Chang S. J Am Chem Soc. 2014; 136:1132-1140. [PubMed: 24377460]

7. For reviews see: Liang Y, Wnuk SF. Molecules. 2015; 20:4874-4901. [PubMed: 25789821] Gayakhe V, Sanghvi YS, Fairlamb IJS, Kapdi AR. Chem Commun. 2015; 51:11944-11960.

8. Lakshman MK, Singh MK, Parrish D, Balachandran R, Day BW. J Org Chem. 2010; 75:2461-2473. [PubMed: 20297785]

9. Lakshman MK, Kumar A, Balachandran R, Day BW, Andrei G, Snoeck R, Balzarini J. J Org Chem. 2012; 77:5870-5883. [PubMed: 22758929]

10. Oi S, Fukita S, Hirata N, Watanuki N, Miyano S, Inoue Y. Org Lett. 2001; 3:2579-2581. [PubMed: 11483065]

11. Xia Q, Chen W. J Org Chem. 2012; 77:9366-9373. [PubMed: 23025235]

12. Murahashi SI, Nakae T, Terai H, Komiya N. J Am Chem Soc. 2008; 130:11005-11012. [PubMed: 18646852]

13. Jin L, Feng J, Lu G, Cai C. Adv Synth Catal. 2015; 357:2105-2110.

14. Crystallographic data for compound 21a (CCDC 1435653) can also be obtained free of charge from the Cambridge Crystallographic Data Center.

15. Tetrahydrofuranyl resonances in compound $23 \mathbf{a}\left(500 \mathrm{MHz}, \mathrm{CDCl}_{3}\right): \delta 6.70\left(\mathrm{~s}, 1 \mathrm{H}, \mathrm{H1}{ }^{\prime}\right), 5.53$ (dd, $\left.J=2.7,6.3 \mathrm{~Hz}, 1 \mathrm{H}, \mathrm{H} 4^{\prime}\right), 4.25\left(\operatorname{app~q}, J=7.5 \mathrm{~Hz}, 1 \mathrm{H}, \mathrm{H} 2^{\prime}\right.$ a), 4.07 (app q, $J=7.5 \mathrm{~Hz}, 1 \mathrm{H}, \mathrm{H} 2^{\prime} \mathrm{b}$ ), $2.71\left(\mathrm{dq}, J=6.9,13.9 \mathrm{~Hz}, 1 \mathrm{H}, \mathrm{H} 3^{\prime} \mathrm{a}\right), 2.35\left(\mathrm{dtd}, J=3.1,7.0,13.6 \mathrm{~Hz}, 1 \mathrm{H}, \mathrm{H} 3^{\prime} \mathrm{b}\right.$ ).

Tetrahydrofuranyl resonances in compound $23 \mathbf{b}\left(500 \mathrm{MHz}, \mathrm{CDCl}_{3}\right): \delta 6.83\left(\mathrm{~s}, 1 \mathrm{H}, \mathrm{H}^{\prime}\right) .5 .17$ (dd, $J=2.4,6.1 \mathrm{~Hz}, 1 \mathrm{H}, \mathrm{H}^{\prime}{ }^{\prime}$ ), $4.36\left(\operatorname{app~q}, J=7.5 \mathrm{~Hz}, 1 \mathrm{H}, \mathrm{H} 2^{\prime}\right.$ a), 4.29 (app q, $J=7.5 \mathrm{~Hz}, 1 \mathrm{H}, \mathrm{H} 2^{\prime} \mathrm{b}$ ), $2.78\left(\mathrm{dq}, J=6.9,13.8 \mathrm{~Hz}, 1 \mathrm{H}, \mathrm{H} 3^{\prime}\right), 2.36-2.27$ (m, 1H, H3' b).

16. Liu X, Chen Y, Li K, Wang D, Chen B. Chin J Chem. 2012; 30:2285-2291.

17. Dian L, Wang S, Zhang-Negrerie D, Du Y, Zhao K. Chem Commun. 2014; 50:11738-11741.

18. Aruri H, Singh U, Sharma S, Gudup S, Bhogal M, Kumar S, Singh D, Gupta VK, Kant R, Vishwakarma RA, Singh PP. J Org Chem. 2015; 80:1929-1936. [PubMed: 25588073]

19. Pan S, Liu J, Li H, Wang Z, Guo X, Li Z. Org Lett. 2010; 12:1932-1935. [PubMed: 20377238]

20. Yang Q, Choy PY, Fu WC, Fan B, Kwong FY. J Org Chem. 2015; 80:11193-11199. [PubMed: 26485515]

21. Murahashi SI, Komiya N, Oda Y, Kuwabara T, Naota T. J Org Chem. 2000; 65:9186-9193. [PubMed: 11149868]

22. Because two products can be formed from any benzotriazole in this reaction, symmetrical 5,6DMBtH was used to simplify product analysis. Unfortunately, the commercial availability of $1 \mathrm{H}$ benzotriazoles in general, and symmetrical ones in particular, is exceptionally limited.

23. Nikalje MD, Sudalai A. Tetrahedron. 1999; 55:5903-5908. 


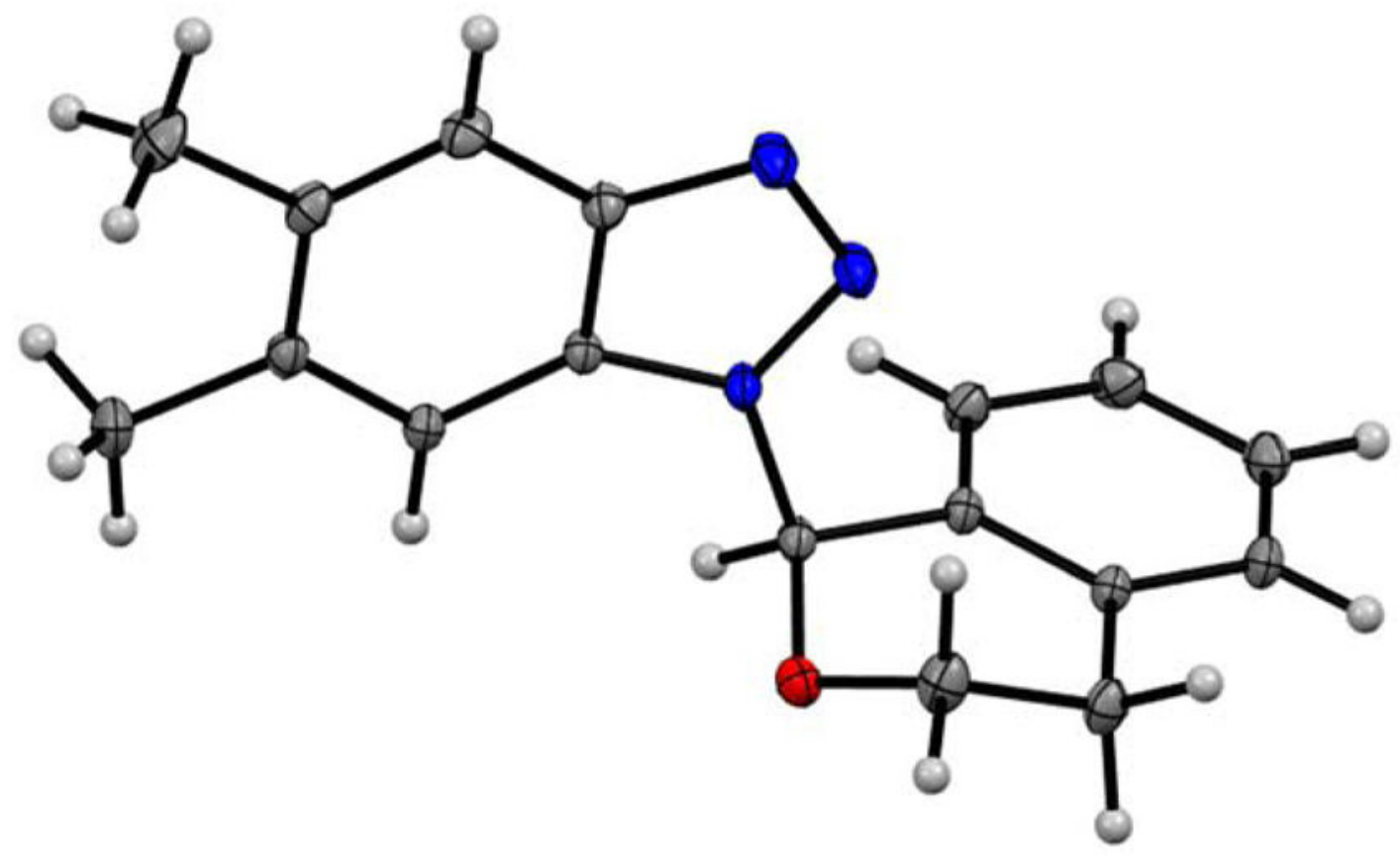

Figure 1.

ORTEP structure of 1-(isochroman-1-yl)-5,6-dimethyl-1 $H$-benzotriazole (21a, CCDC 1435653 , thermal ellipsoids are shown at 50\% probability level). 


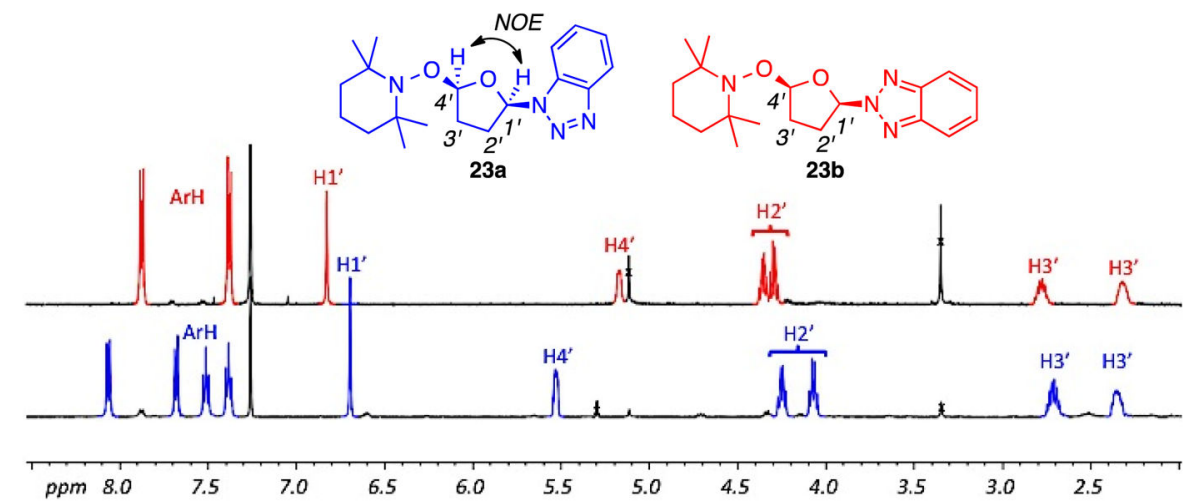

Figure 2.

Partial $500 \mathrm{MHz}{ }^{1} \mathrm{H}$ NMR spectra of isomeric compounds $\mathbf{2 3 a}$ and $\mathbf{2 3 b}$ in $\mathrm{CDCl}_{3}$ showing the tetrahydrofuranyl protons. 

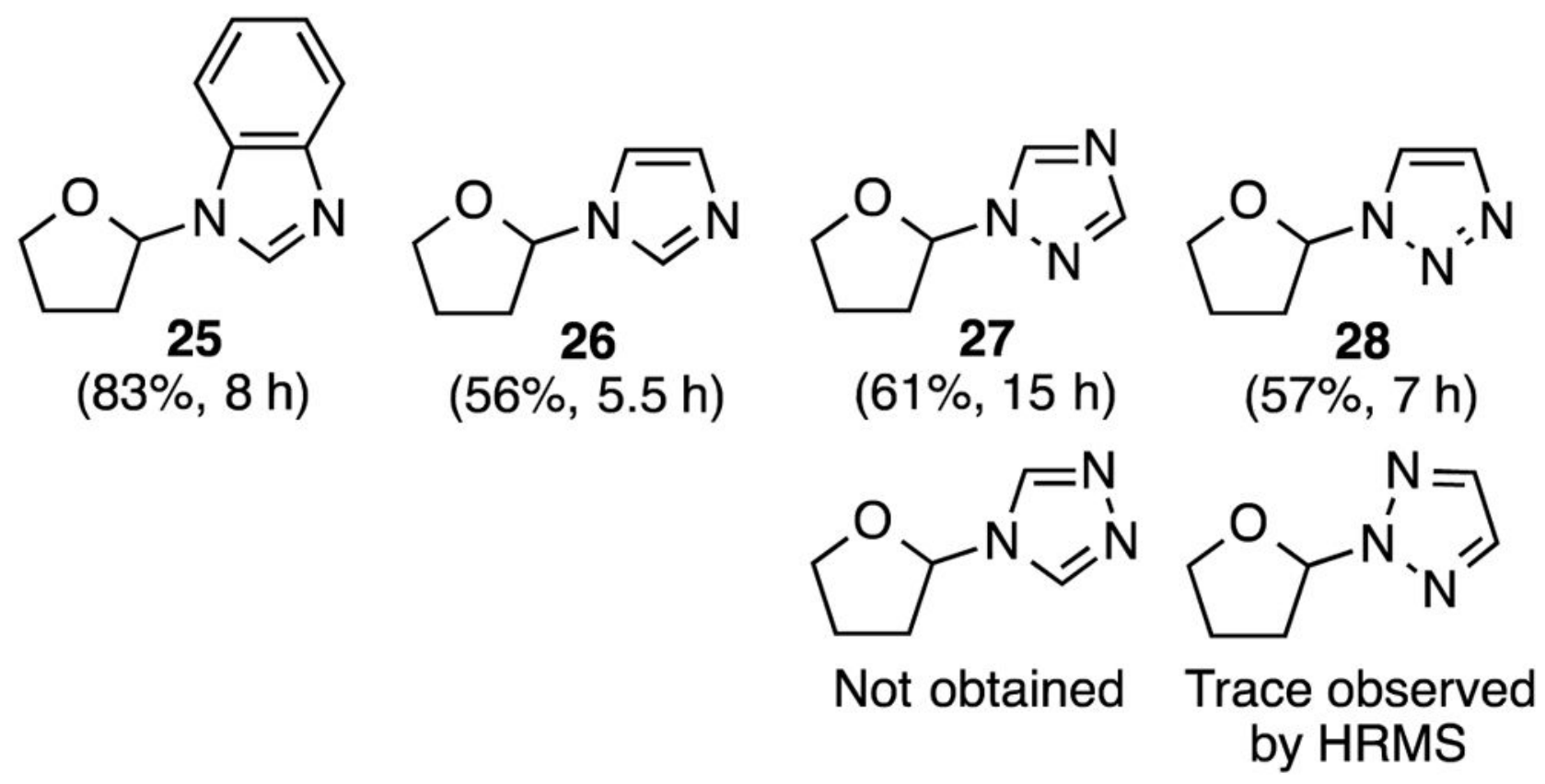

Figure 3.

Products obtained from reactions of benzimidazole, imidazole, 1,2,4-triazole, and 1,2,3triazole with THF, catalyzed by $\mathrm{RuCl}_{3} / t-\mathrm{BuOOH}$. 


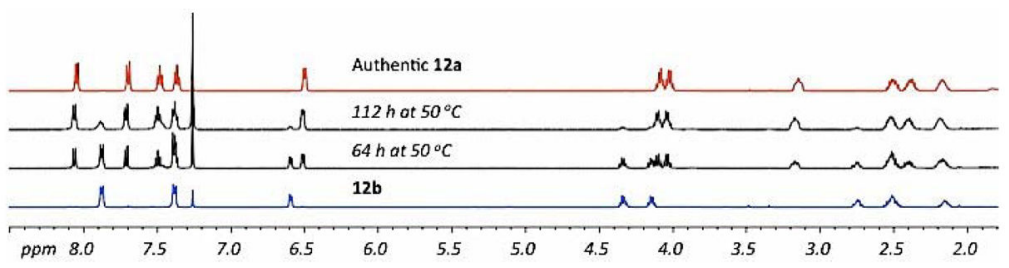

Figure 4.

Isomerization of 2-(tetrahydrofuran-2-yl)-2 $H$-1,2,3-benzotriazole (12b) to 1(tetrahydrofuran-2-yl)-1 $H$-1,2,3-benzotriazole (12a) at $50{ }^{\circ} \mathrm{C}$ in a NMR tube. 

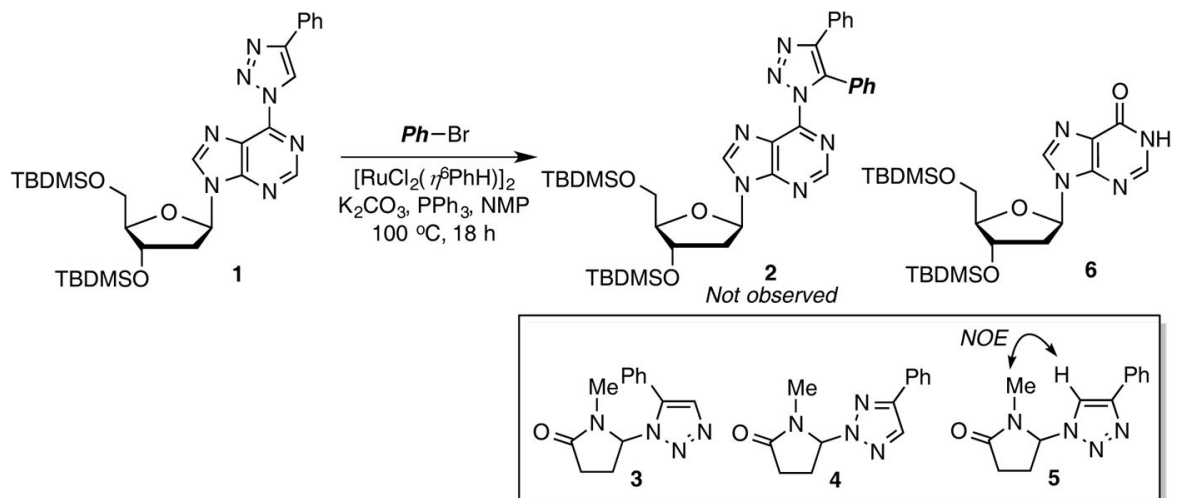

NOE

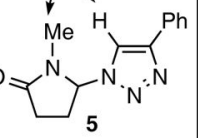

Scheme 1.

Attempted Ru-catalyzed N-directed arylation of a C-6 triazolyl purine nucleoside resulting in a triazolyl NMP derivative 


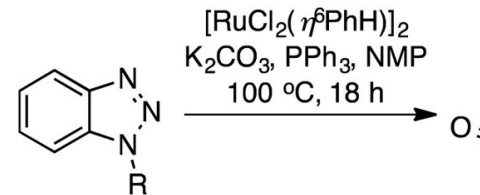

7: $\mathrm{R}=\mathrm{OTs}$

9: $\mathrm{R}=\mathrm{H}$

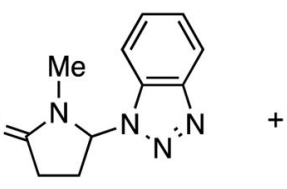

8a: $51 \%$ from 7

8a: $28 \%$ from 9

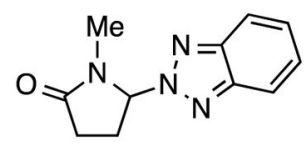

$8 b: 18 \%$ from 7

8b: $5 \%$ from 9

Scheme 2.

$\mathrm{Ru}$-catalyzed reactions of Bt-OTs and BtH with NMP 


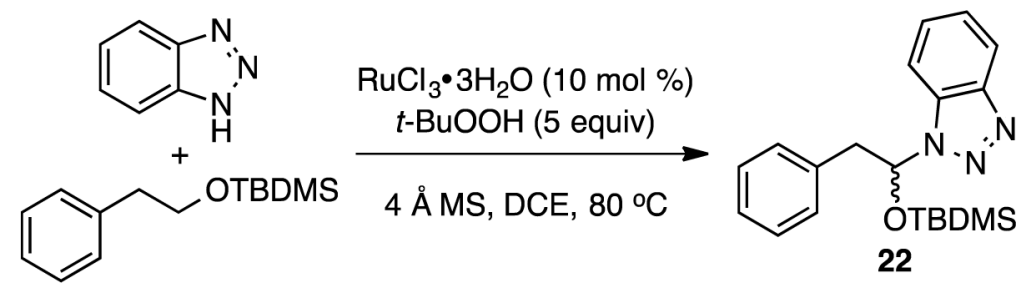

Scheme 3 .

Ru-catalyzed C-H bond-activation of 2-phenylethanol TBDMS ether 


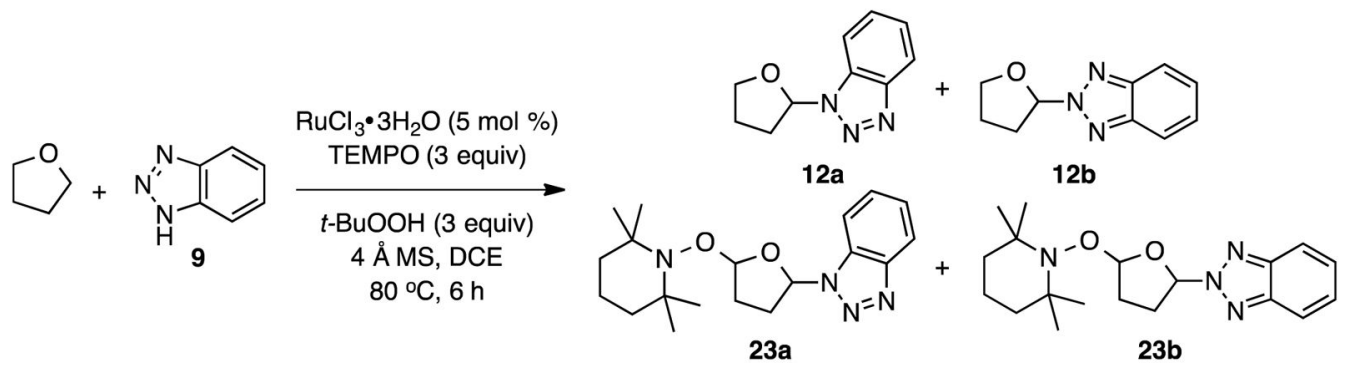

Scheme 4.

Reaction between THF and BtH in the presence of TEMPO 


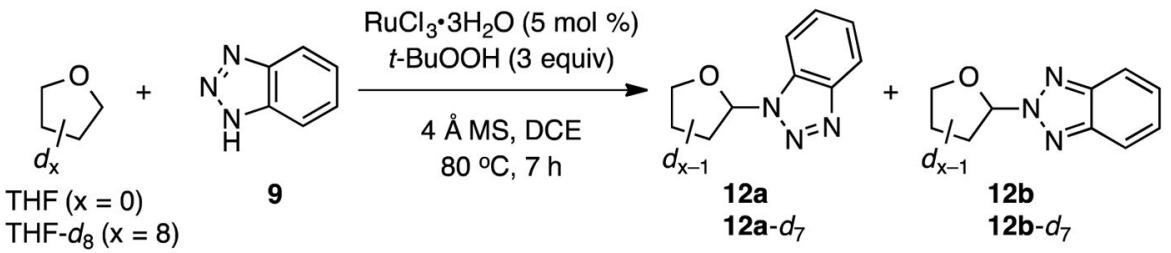

Scheme 5.

Competitive reaction of $\mathrm{BtH}$ with $\mathrm{THF}$ and $\mathrm{THF}-d_{8}$ 


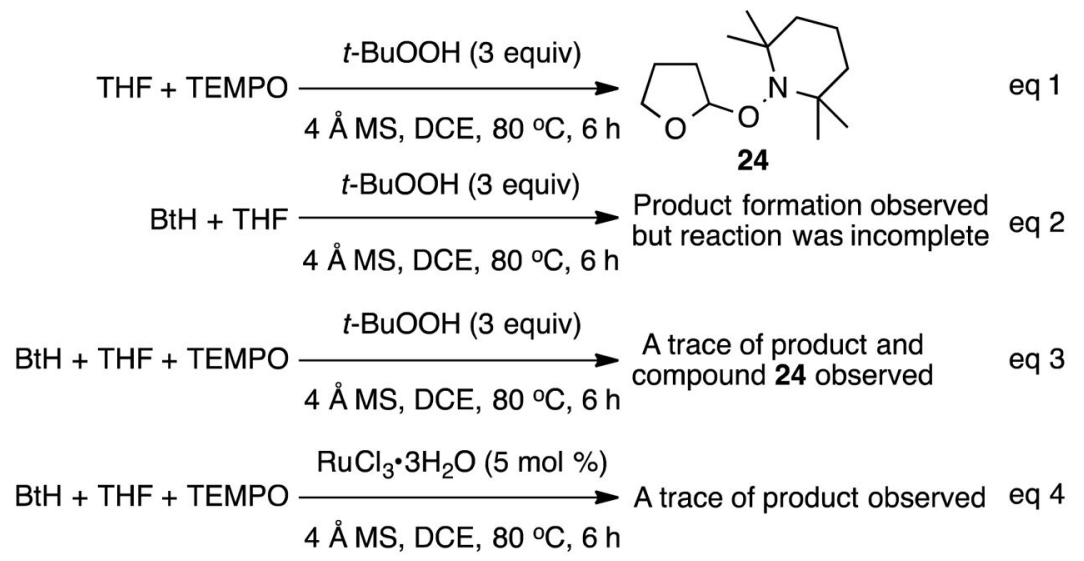

Scheme 6.

Additional experiments to gain mechanistic insight 


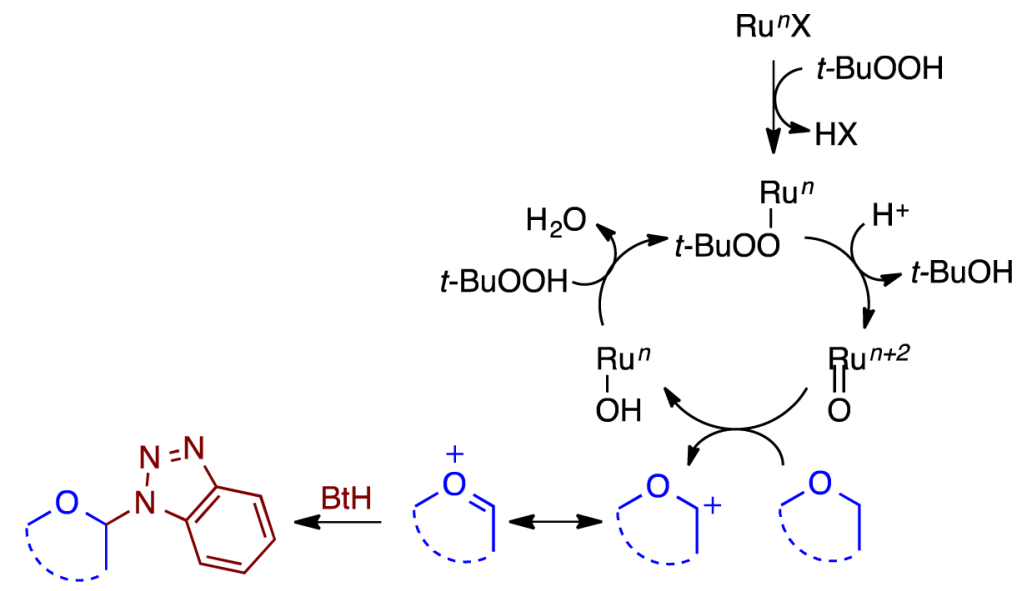

Scheme 7.

A plausible reaction mechanism 


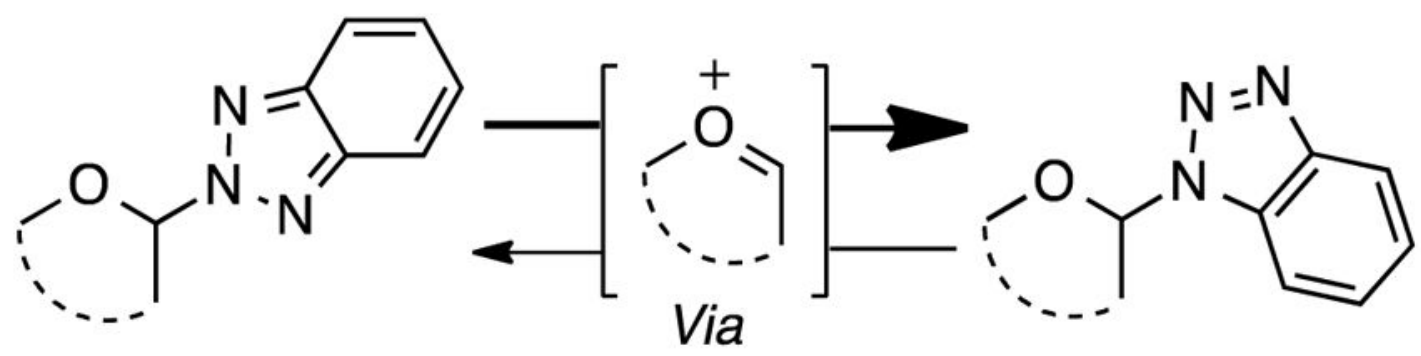

Scheme 8.

Predominant isomerization of the $N 1$ to the $N 2$ isomers 


\section{Table 1}

Conditions tested for the C-H Bond Activation of NMP ${ }^{a}$

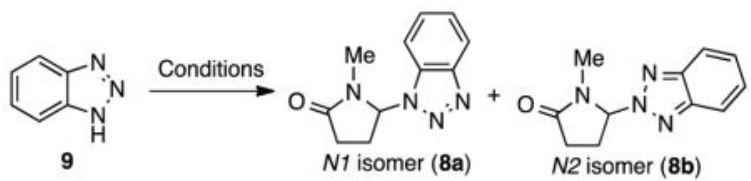

\begin{tabular}{|c|c|c|c|}
\hline entry & catalyst & reagents and conditions & yield $(\%)^{b}$ \\
\hline 1 & {$\left[\mathrm{RuCl}_{2}\left(\eta^{6} \mathrm{PhH}\right)\right]_{2}$} & NMP, 2 equiv $\mathrm{K}_{2} \mathrm{CO}_{3}, 1 \mathrm{~atm}$. of $\mathrm{O}_{2}, 18 \mathrm{~h}$ at $100{ }^{\circ} \mathrm{C}$ & $N 1: 23, N 2: 22$ \\
\hline 2 & {$\left[\mathrm{RuCl}_{2}\left(\eta^{6} \text {-p-cymene }\right)\right]_{2}$} & NMP, 2 equiv $\mathrm{K}_{2} \mathrm{CO}_{3}, 1 \mathrm{~atm}$. of $\mathrm{O}_{2}, 5 \mathrm{~h}$ at $100{ }^{\circ} \mathrm{C}$ & $N 1: 16, N 2: 12$ \\
\hline 3 & {$\left[\mathrm{Ru}(\mathrm{CO})(\mathrm{H})_{2}\left(\mathrm{PPh}_{3}\right)_{3}\right]$} & NMP, 2 equiv $\mathrm{K}_{2} \mathrm{CO}_{3}, 1 \mathrm{~atm}$. of $\mathrm{O}_{2}, 48 \mathrm{~h}$ at $100{ }^{\circ} \mathrm{C}$ & Incomplete $^{c}$ \\
\hline 4 & $\mathrm{RuCl}_{3} \cdot 3 \mathrm{H}_{2} \mathrm{O}$ & NMP, 2 equiv $\mathrm{K}_{2} \mathrm{CO}_{3}, 1$ atm. of $\mathrm{O}_{2}, 16 \mathrm{~h}$ at $100{ }^{\circ} \mathrm{C}$ & $N 1: 18, N 2: 5$ \\
\hline 5 & $\mathrm{RuCl}_{3} \cdot 3 \mathrm{H}_{2} \mathrm{O}$ & NMP, 2 equiv $\mathrm{K}_{2} \mathrm{CO}_{3}, 6$ equiv $t$ - $\mathrm{BuOOH}$ in $\mathrm{H}_{2} \mathrm{O}, 16 \mathrm{~h}$ at $\mathrm{rt}$ & $N 1: 41, N 2: 9$ \\
\hline 6 & $\mathrm{RuCl}_{3} \cdot 3 \mathrm{H}_{2} \mathrm{O}$ & 6 equiv NMP, 2 equiv $\mathrm{K}_{2} \mathrm{CO}_{3}, 6$ equiv $t-\mathrm{BuOOH}$ in $\mathrm{H}_{2} \mathrm{O}, 16 \mathrm{~h}$ at $\mathrm{rt}$ & $N 1: 40, N 2: 28$ \\
\hline 7 & $\mathrm{RuCl}_{3} \cdot 3 \mathrm{H}_{2} \mathrm{O}$ & $\begin{array}{l}3 \text { equiv NMP, } \mathrm{H}_{2} \mathrm{O},{ }^{d} 2 \text { equiv } \mathrm{K}_{2} \mathrm{CO}_{3}, 2.5 \text { equiv } t-\mathrm{BuOOH} \text { in } \mathrm{H}_{2} \mathrm{O}, 18 \mathrm{~h} \text { at } \mathrm{rt} \text {, then } 4 \mathrm{~h} \text { at } \\
60{ }^{\circ} \mathrm{C}\end{array}$ & $N 1: 13, N 2: 5$ \\
\hline 8 & $\mathrm{RuCl}_{3} \cdot 3 \mathrm{H}_{2} \mathrm{O}$ & 10 equiv NMP, DCE, ${ }^{e} 3$ equiv $t$ - $\mathrm{BuOOH}$ in nonane, $7 \mathrm{~h}$ at $80^{\circ} \mathrm{C}$ & $N 1: 53, N 2: 13$ \\
\hline 9 & None & 10 equiv NMP, DCE, ${ }^{e} 3$ equiv $t$-BuOOH in nonane, $29 \mathrm{~h}$ at $80^{\circ} \mathrm{C}$ & Incomplete ${ }^{c}$ \\
\hline
\end{tabular}

${ }^{a}$ All reactions were conducted in $1 \mathrm{~mL}$ of solvent (NMP, $\mathrm{H}_{2} \mathrm{O}$, or DCE), unless noted otherwise. BtH concentration in entries 1-5 and 7-9: 0.5 M, and in entry 6: $1.7 \mathrm{M}$. Catalyst: $10 \mathrm{~mol} \%$ in entries $1-7$ and $5 \mathrm{~mol} \%$ in entry 8 .

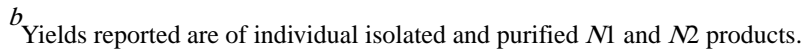

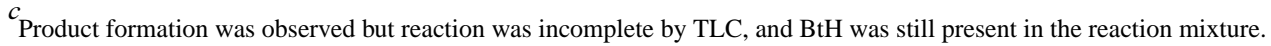

$d_{\text {Water was used as the reaction solvent. }}$

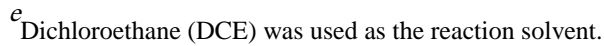


Table 2

Ru-catalyzed alkylation of $\mathrm{BtH}$ and 5,6-DMBtH with NMP and ethers ${ }^{a}$

\begin{tabular}{llll}
\hline entry & reactants & products & results ${ }^{b}$ \\
\hline 1 & Time =7h \\
8a: 53\%, 8b: 13\% \\
Total yield =66\% \\
$N 1 / N 2=4.1: 1$
\end{tabular}

2<smiles>Cc1cc2nn[nH]c2cc1C</smiles>

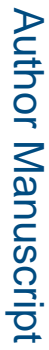

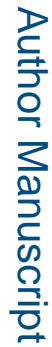

3<smiles>c1ccc2[nH]nnc2c1</smiles><smiles>C1CCOC1</smiles><smiles>Cc1cc2nnn(C3CCC(=O)N3C)c2cc1C</smiles>

11a<smiles>c1ccc2c(c1)nnn2C1CCCO1</smiles>

$12 a$<smiles></smiles>

12b<smiles>Cc1cc2nn[nH]c2cc1C</smiles><smiles>C1CCOC1</smiles>

5<smiles>c1ccc2[nH]nnc2c1</smiles>

6<smiles>Cc1cc2nn[nH]c2cc1C</smiles><smiles>Cc1cc2nnn(C3CCCO3)c2cc1C</smiles>

$13 a$<smiles>Cc1cc2nn(C3CCCO3)nc2cc1C</smiles>

Time $=7 \mathrm{~h}$

11a: $55 \%, 11 b: 20 \%$

Total yield $=75 \%$

$N 1 / N 2=2.7: 1$

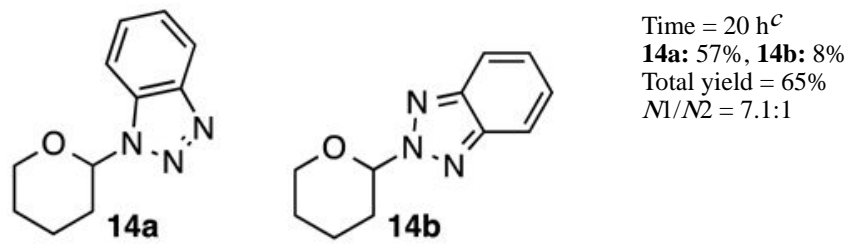

Time $=24 \mathrm{~h}$

15a: $31 \%, \mathbf{1 5 b}: 15 \%$

Total yield $=46 \%$<smiles>Cc1cc2nnn(C3OCCCC3(C)C)c2cc1C</smiles><smiles></smiles>

Time $=6 \mathrm{~h}$

13a: $47 \%$, 13b: $21 \%$

Total yield $=68 \%$

$N \mathrm{l} / N 2=2.1: 1$ 


\begin{tabular}{|c|c|c|}
\hline entry & 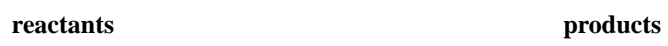 & results $b$ \\
\hline 7 & & $\begin{array}{l}\text { Time }=16 \mathrm{~h} \\
\text { 16a: } 46 \%, \mathbf{1 6 b}: 27 \% \\
\text { Total yield }=73 \% \\
N 1 / N 2=1.7: 1\end{array}$ \\
\hline
\end{tabular}

8<smiles>CCOCC</smiles><smiles>CCOC(C[Te])n1nnc2cc(C)c(C)cc21</smiles>

Time $=3.5 \mathrm{~h}$

17a: $40 \%$, 17b: $28 \%$

Total yield $=68 \%$ $N \mathrm{l} / N 2=1.4: 1$<smiles>c1ccc2[nH]nnc2c1</smiles><smiles>C1COCCO1</smiles><smiles>Cc1cc2nn[nH]c2cc1C</smiles>

11<smiles>c1ccc2c(c1)CCOC2</smiles><smiles>CC(C)(C)[C@H]1OCCOC1n1nnc2ccccc21</smiles><smiles>CCOC(C)n1nc2cc(C)c(C)cc2n1</smiles>

$17 b$<smiles>O=C(c1ccccc1)C1OCCOC1n1nc2ccccc2n1</smiles>

Time $=24 \mathrm{~h}^{c, d}$

18a: $29 \%$, 18b: $17 \%$

Total yield $=46 \%$

$N \mathrm{l} / N 2=1.7: 1$

Time $=24 \mathrm{~h} c, d, e$

18a: $27 \%$, 18b: $18 \%$

Total yield $=45 \%$

$N 1 / N 2=1.5: 1$

Time $=24 \mathrm{~h}^{c, d}$

19a: $23 \%$, 19b: $7 \%$

Total yield $=30 \%$

$N \mathrm{l} / N 2=3.3: 1$<smiles>Cc1cc2nnn(C3OCCOC3[SeH])c2cc1C</smiles><smiles>Cc1cc2nn(C3OCCOC3[SeH3])nc2cc1C</smiles>

Time $=8 \mathrm{~h}$

20a: $53 \%$, 20b: $4 \%$

Total yield $=57 \%$

$N \mathrm{l} / N 2=13.2: 1$<smiles></smiles><smiles></smiles>

Time $=8 \mathrm{~h}$

12<smiles>Cc1cc2nn[nH]c2cc1C</smiles><smiles>CCCOC1OCCc2ccccc21</smiles><smiles>Cc1cc2nn(C3OCCc4ccccc43)nc2cc1C</smiles>

Total yield $=62 \%$

$N \mathrm{l} / N 2=19.7: 1$

\footnotetext{
${ }^{a}$ Reactions were conducted at $0.5 \mathrm{M}$ concentration of $\mathrm{BtH}$ or 5,6-DMBtH in DCE, with 10 equiv of NMP or ether, 5 mol $\% \mathrm{RuCl}_{3} \cdot 3 \mathrm{H}_{2} \mathrm{O}, 3$ equiv
} $t$ - $\mathrm{BuOOH}$ in nonane, at $80^{\circ} \mathrm{C}$ (except where noted otherwise). Molecular sieves $(4 \AA, 0.2 \mathrm{~g}$ ) were used for reactions of ethers. 
$b_{\text {Yields reported are of isolated and purified products, and they are not based on recovered benzotriazole (see the Supporting Information for }}$ amounts of benzotriazoles recovered).

${ }^{c}$ Reaction remained incomplete.

${ }^{d}$ Reaction was conducted at $110-120^{\circ} \mathrm{C}$.

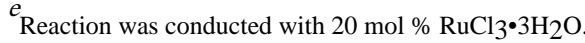




\section{Table 3}

Observed KIE values for comparable C-H bond activations with THF/THF- $d_{8}$

entry reactants


Table 4

Comparison of three methods for synthesis of benzotriazolyl hemiaminal ethers

\begin{tabular}{|c|c|c|c|}
\hline ether & $\mathrm{FeCl}_{3} / t-\mathrm{BuOOH}$ & $n-\mathrm{Bu}_{4} \mathrm{~N}^{+} \mathrm{I}^{-} / t-\mathrm{BuOOH}$ & $\mathrm{RuCl}_{3} / t-\mathrm{BuOOH}$ \\
\hline & Only $N 1$ isomer reported, $74 \%{ }^{16}$ & $\begin{array}{l}N 1: N 2=3.4: 1,87 \% 1^{17} \\
N 1: N 2=1.9: 1,98 \% 18\end{array}$ & $N 1: N 2=3.2: 1,84 \%$ \\
\hline & Only $N 1$ isomer reported, $55 \%{ }^{16}$ & $N 1: N 2=1.4: 1,85 \%{ }^{18}$ & $N 1: N 2=1.7: 1,46 \%$ \\
\hline & - & $N \mathrm{l}=60 \%(\text { only isomer reported })^{18}$ & $N 1: N 2=7.1: 1,65 \%$ \\
\hline & - & $N 1: N 2=5.5: 1,65 \%{ }^{18}$ & $N 1: N 2=1.7: 1,73 \%$ \\
\hline
\end{tabular}




\section{Table 5}

Comparison of reactions of benzimidazole, imidazole, 1,2,4-triazole, and 1,2,3-triazole with THF under various conditions ${ }^{a}$

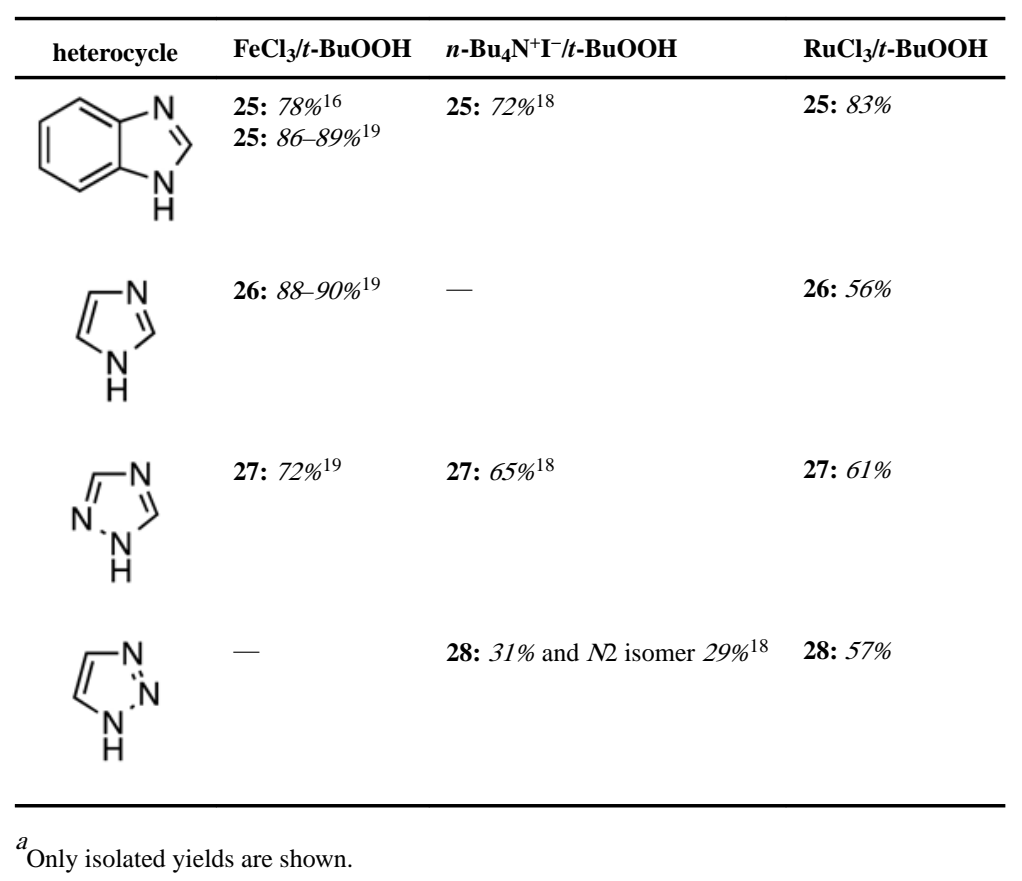

